Article

\title{
Functional and Pharmacological Analyses of the Role of Penicillium digitatum Proteases on Virulence
}

\author{
Ana-Rosa Ballester (D), Mario López-Pérez ${ }^{\dagger}$, Beatriz de la Fuente ${ }^{\ddagger}$ and Luis González-Candelas *(D) \\ Department of Food Biotechnology, Institute of Agrochemistry and Food Technology, Spanish National Research \\ Council (IATA-CSIC), Calle Catedrático Agustín Escardino 7, 46980 Paterna, Valencia, Spain \\ * Correspondence: lgonzalez@iata.csic.es; Tel.: +34-963-900-022 \\ † Present address: Evolutionary Genomics Group, División de Microbiología, Universidad Miguel Hernández, \\ Apartado 18, 03550 San Juan, Alicante, Spain. \\ $\ddagger$ Present address: Nutrition and Food Science Area, Preventive Medicine and Public Health, Food Science, \\ Toxicology and Forensic Medicine Department, Faculty of Pharmacy, Universitat de València, Avda. Vicent \\ Andrés Estellés, 46100 Burjassot, València, Spain.
}

Received: 6 June 2019; Accepted: 11 July 2019; Published: 12 July 2019

\begin{abstract}
Penicillium digitatum is the major postharvest pathogen of citrus fruit under Mediterranean climate conditions. Previous results have shown that proteases is the largest enzyme family induced by $P$. digitatum during fruit infection. In the present work, we addressed the study of the role of P. digitatum's proteases in virulence following two complementary approaches. In the first approach, we undertook the functional characterization of the P. digitatum prtT gene, which codes for a putative transcription factor previously shown to regulate extracellular proteases in other filamentous fungi. Deletion of prtT caused a significant loss in secreted protease activity during in vitro growth assays. However, there was no effect on virulence. Gene expression of the two major secreted acid proteases was barely affected in the $\Delta p r t T$ deletant during infection of citrus fruit. Hence, no conclusion could be drawn on the role of these secreted acidic proteases on the virulence of P. digitatum. In the second approach, we studied the effect of different protease inhibitors and chelators on virulence. Co-inoculation of citrus fruit with P. digitatum conidia and a cocktail of protease inhibitors resulted in almost a complete absence of disease development. Analysis of individual inhibitors revealed that the metalloprotease inhibitor, 1,10-phenanthroline, was responsible for the observed effect. The application of metal ions reverted the protective effect caused by the metallopeptidase inhibitor. These results may set the basis for the development of new alternative treatments to combat this important postharvest pathogen.
\end{abstract}

Keywords: Agrobacterium tumefaciens mediated transformation; citrus fruit; metal ion chelators; fruit-fungal interaction; transcription factor; virulence; protease inhibitors

\section{Introduction}

Proteases, also denoted as peptidases, proteinases, or proteolytic enzymes, can be classified according to the nature of the functional group at the active site. Most proteases belong to one of the four major families: Aspartic, cysteine, metallo, and serine peptidases. They are widely used in biotechnology, mainly in the food, leather, and detergent industries, in ecological bioremediation processes, and to produce therapeutic peptides [1]. They comprise a large number of proteins that account for a significant proportion of an organism's gene count. Thus, species in the genera, Aspergillus or Penicillium, contain more than 200 and 100 annotated genes encoding for putative proteases in the MEROPS database (https://www.ebi.ac.uk/merops/), respectively. These enzymes play a major role in the physiology, morphogenesis, and metabolism of fungi. Their production is regulated in response to 
environmental signals, such as extracellular $\mathrm{pH}$ and carbon and nitrogen sources [2]. Proteases secreted into the environment play a crucial role in nutrition because they are needed for external digestion of macromolecular nutrients. In addition to nutrient utilization, microbial proteases are involved in many physiological processes, such as morphogenesis, germination, and conidial discharge [3]. Proteases play an important role in the mechanism of the virulence of pathogens by participating in the penetration and dissemination within the host, as well as by combating the host's defense mechanisms [4-7]. The role of fungal proteases in plant infection has been less characterized than that of bacterial and animal pathogens. For example, Sclerotinia sclerotiorum produced aspartyl proteases, non-aspartyl acidic proteases, and serine proteases during infection of sunflower, and the increase of protease production was correlated with intensive colonization and maceration of the host tissues [8]. A UV-induced mutant of the tomato pathogen Colletotrichum coccodes defective in extracellular protease activity was unable to infect tomato fruits, although it showed normal vegetative growth and cellulase activity [9]. In Fusarium oxysporum f. sp. lycopersici, the synergistic action of a serine protease, FoSep1, and a metalloprotease, FoMep1, was required for cleavage and removal of the chitin-binding domain (CBD) from two tomato CBD-chitinases [10]. In addition, mutants of F. oxysporum f. sp. lycopersici lacking both FoSep1 and FoMep1 exhibited reduced virulence on tomato, confirming that secreted fungal proteases are important virulence factors by targeting CDB-chitinases to compromise an important component of the plant's basal defense [10]. Fungalysins are a conserved family of metalloproteases in fungi and their role as chitinase-degrading enzymes has been demonstrated in Colletotrichum graminicola. The absence of the fungalisyn metalloprotease-encoding CgfI gene delayed fungal development during the infection process on maize leaves and, in parallel, maize leaves exhibit increased chitinase activity, suggesting that the fungus employs a CgfI-mediated strategy to control chitin signaling [11]. Botrytis cinerea is a typical necrotroph that secretes aspartic proteases during infection on various plant tissues. However, single or double deletant mutants in five genes encoding aspartic proteases did not result in any defect in virulence [12].

PrtT is a fungal-specific transcription activator of extracellular proteases that was first isolated and characterized in Aspergillus niger [13]. It is present in several Aspergilli and Penicillia, but absent in the genome of Aspergillus nidulans [14]. This transcription factor belongs to the fungal-specific $\mathrm{Gal}_{4}$-like $\mathrm{Zn}_{2} \mathrm{Cys}_{6}$ binuclear cluster protein family and plays an important role in the production of secreted proteases. Disruption of prtT in $A$. niger resulted in transformants unable to form a protease degradation halo on plates containing skim milk [13]. Moreover, an Aspergillus oryzae prtT disruption mutant produced lower levels of the alkaline serine protease S8 (AlpA) and to a lesser extent, the neutral metalloprotease M36 (NpI) compared to the wild type, confirming the role of PrtT in the regulation of the major proteases in this fungus [13]. Unexpectedly, microarray analysis revealed that the expression of genes involved in iron uptake and ergosterol synthesis was dramatically decreased in the Aspergillus fumigatus $\Delta$ prtT mutant, together with an upregulation of different secondary metabolite clusters [15]. However, in two independent works, this transcription factor was found to be not essential for virulence in this human opportunistic fungal pathogen, suggesting that either residual protease activity is sufficient to enable virulence or that proteases are dispensable for pathogenicity in this fungus [14,16]. Regarding the genus Penicillium, PrtT has been only characterized in Penicillium oxalicum. A transcription profiling analysis using RNA-Seq showed that many putative peptidase-encoding genes were either up- or down-regulated in a P. oxalicum $\Delta p r t T$ mutant, including both secreted and intracellular proteases [17], confirming that PrtT is a global regulator of proteases. In addition, this transcriptomic study found that PrtT putatively regulates the transcription of specific amylases and major facilitator superfamily (MFS) transporters involved in the transport of nutrients, and of specific transporters and enzymes involved in lignocellulose degradation in response to nutrient limitation.

Penicillium digitatum is the most important postharvest pathogen of citrus fruit grown under Mediterranean conditions. It is a necrotrophic fungus that requires wounds in the fruit peel to penetrate and colonize the fruit tissue mostly through the deployment of maceration enzymes. The genome of this fungus contains 275 putative carbohydrate-active enzymes (CAZymes) assigned mostly to 
glycoside hydrolases, carbohydrate esterases, and polysaccharide lyases, among others, and to a lesser extent, to enzymes related to the degradation of cellulose and hemicellulose [18]. In comparison with other Penicillium spp., P. digitatum is enriched in polygalacturonases and pectinesterases, both involved in pectin degradation. This necrotrophic fungus possesses a small secretome compared to Penicillium expansum or Penicillium italicum, and proteases constitute a large proportion of its secretome [19]. The genome of $P$. digitatum encodes 119 proteases and 29 non-peptidase homologs (MEROPS peptidase database for P. digitatum, release 12.1, April 2019) [20]. The most abundant category corresponds to the superfamily of serine proteases, followed by metallo and cysteine proteases. In a previous study, we observed that genes coding for putative fungal proteases and plant cell wall-degrading enzymes represent the largest categories during the orange- $P$. digitatum interaction, with five secreted protease-encoding genes being among the most highly expressed genes during fruit infection [21]. In this report, we aim to analyze the role of $P$. digitatum proteases on virulence. In view of the large number of secreted proteases, we focused on PrtT, which regulates extracellular proteases, with the aim of reducing the production of secreted proteases as much as possible while avoiding the gene compensation effects observed when eliminating a single member of a large gene family. If the major proteases were regulated by PrtT, knocking out the corresponding gene could offer an alternative to study to the role of $P$. digitatum proteases in virulence. For this purpose, we followed a functional approach by constructing and characterizing a deletion mutant of the prtT gene. In addition, we undertook a pharmacological approach by using a set of protease inhibitors during the infection of citrus fruit by $P$. digitatum. Our results showed that 1,10-phenanthroline, a metalloprotease inhibitor, is able to control the development of $P$. digitatum in citrus fruit.

\section{Materials and Methods}

\subsection{Fungal Strains and Growth Conditions}

Penicillium digitatum (Pers.:Fr.) Sacc. strain Pd1 (PDIP, deposited at the Spanish Type Culture Collection with accession code CECT20795) was isolated from an infected grapefruit [18]. To prepare conidial suspensions, the strain was grown on potato-dextrose-agar (PDA) at $24{ }^{\circ} \mathrm{C}$ for 7 days. Conidia were scraped off the agar with a sterile spatula, suspended in sterile distilled water, and filtered through a nylon mesh. Conidia concentration was determined with a hemocytometer.

\subsection{Generation and Verification of P. digitatum prtT Mutants}

A BlastP search with the sequence of PrtT from A. niger (accession number XM_001402018.2) as the query was performed against the P. digitatum Pd1 proteome [18]. To construct the prtT gene replacement plasmid, $1.8 \mathrm{~kb}$ upstream and downstream flanking fragments of the prtT gene (PDIP_25240) were amplified from genomic DNA of P. digitatum (Pd1/PDIP), using the specific primers O1, O2, A3, and A4 (Table 1). These primers include vector-specific 9 bp long overhangs containing a single 2-deoxyuridine nucleoside in the $5^{\prime}$ end, which ensured directionality in the cloning reaction. The two flanking fragments were introduced into pRF-HU2 following the USER (uracil-specific excision reagent) protocol described by Frandsen et al. [22]. The resulted plasmid (denoted as pDprtT) was introduced into Escherichia coli $\mathrm{DH} 5 \alpha$ chemical competent cells. Kanamycin-resistant transformants were screened by PCR for the presence of the promoter and the terminator with primer pairs RF1/RF6 and RF2/RF5, respectively (Table 1). Proper fusions were further confirmed by DNA sequencing and then the plasmid was transferred to Agrobacterium tumefaciens AGL1 electrocompetent cells. Transformation of P. digitatum Pd1 was done as previously described [18]. Equal volumes of induced bacterial culture and conidial suspension of P. digitatum strain $\operatorname{Pd} 1\left(10^{5}\right.$ conidia $\left./ \mathrm{mL}\right)$ were mixed and spread onto filter papers, which were placed on agar plates containing the co-cultivation medium. After co-cultivation at $24^{\circ} \mathrm{C}$ for $48 \mathrm{~h}$, the membranes were transferred to PDA plates containing $100 \mu \mathrm{g} / \mathrm{mL}$ of hygromycin B (InvivoGen, San Diego, CA, USA), as the selection agent for fungal transformants, and $200 \mu \mathrm{g} / \mathrm{mL}$ of cefotaxime (Calbiochem, San Diego, CA, USA) to inhibit the growth of $A$. tumefaciens cells. Hygromycin-resistant 
colonies appeared after 4 to 5 days of incubation at $24^{\circ} \mathrm{C}$. To ensure correct deletion of the prtT gene and the absence of ectopic insertions, conventional PCR and quantitative PCR (qPCR) were used to determine the gene copy number of the T-DNA inserted in P. digitatum. Firstly, disruption of the prtT gene was confirmed by PCR analyses of the transformants. Integration of the T-DNA by homologous recombination was examined using primer pairs HPHTER2/1F and HPHRO4/4R (Table 1) for the promoter and the terminator regions, respectively. Further verification of deletion of the target gene and the insertion of the hygromycin marker was done with primers 5F/6R followed by digestion with EcoRI. To determine the number of T-DNA molecules that had been integrated into the genome of each selected transformant, a qPCR analysis was carried out following an already demonstrated methodology described by several authors $[21,23,24]$, using Pd1 DNA as the control. A primer pair $(7 \mathrm{~F} / 8 \mathrm{R})$ was designed within the T-DNA in the terminator region of the target gene, close to the selection marker. The P. digitatum actin gene (PDIP_18200) was chosen as a reference using the primer pair PdACTFor2/PdACTRev2 (Table 1). qPCR reactions were performed in a LightCycler480 System (Roche Diagnostics, Basel, Switzerland) using SYBR Green to monitor DNA amplification. For each primer pair and each sample, the PCR efficiencies (E) and the quantification cycle (Cq) were assessed using the LinRegPCR software version 2017.1 [25]. The number of T-DNA copies that were integrated in the genome of the transformants was calculated according to the formula: Copy number $=\left(\mathrm{E}_{\text {target gene }}\right)^{\wedge} \Delta \mathrm{C} \mathrm{q}_{\text {target gene }}{ }^{\text {(wild type }- \text { transformant })} /\left(\mathrm{E}_{\text {reference gene }}\right)$ ${ }^{\wedge} \Delta \mathrm{Cq}$ reference gene (wild type - transformant) based on Pfaffl [26], which depends on $\mathrm{E}$ and the Cq value of the transformant versus the wild-type strain, and normalized in comparison to a reference gene that is present with the same copy number in both wild-type and transformant strains.

Table 1. Primers used in the study. The $5^{\prime}$ deoxyuridine extension parts in the primers used for the assembly of the USER cloning sites are indicated in bold.

\begin{tabular}{|c|c|}
\hline Primer Name & Sequence $\left(5^{\prime} \rightarrow 3^{\prime}\right)$ \\
\hline \multicolumn{2}{|c|}{ Knockout mutant construction } \\
\hline $\mathrm{O} 1$ & GGTCTTAAUTCAACTTGCGTGCTATGATTGAAGGCCT \\
\hline $\mathrm{O} 2$ & GGCATTAAUTGAGCGAGGACTTTTAGCCAATTGCGA \\
\hline A3 & GGACTTAAUTAATTGTCTCGAGCAGATGATGCCTGGG \\
\hline A4 & GGGTTTAAUGGTACACTCAGACAGCCGTGGAAGCAAA \\
\hline \multicolumn{2}{|l|}{ Knockout mutant analysis } \\
\hline RF1 & AAATTTTGTGCTCACCGCCTGGAC \\
\hline RF2 & TCTCCTTGCATGCACCATTCCTTG \\
\hline RF5 & GTTTGCAGGGCCATAGAC \\
\hline RF6 & ACGCCAGGGTTTTCCCAGTC \\
\hline HPHPRO4 & GCACCAAGCAGCAGATGATA \\
\hline $1 \mathrm{~F}$ & TATGAGGGGTTGTGGCTTTC \\
\hline HPHTER2 & GCTCCGTAACACCCAATAC \\
\hline $4 \mathrm{R}$ & CAAACTCGCAAGAGCCCTAC \\
\hline $5 \mathrm{~F}$ & TTTGAATCGTGCCACTCACC \\
\hline $6 \mathrm{R}$ & ATCGGCATAGCTCCACCAGT \\
\hline \multicolumn{2}{|c|}{ Determination of T-DNA copy number } \\
\hline $7 \mathrm{~F}$ & GCGTTGCATGATTGGTGATG \\
\hline $8 \mathrm{R}$ & AGCACAACACAACACCCAAG \\
\hline PdACTFor2 & TGTCACCAACTGGGACGATA \\
\hline PdACTRev2 & GAGCTTCGGTCAAGAGGATG \\
\hline \multicolumn{2}{|l|}{ Gene expression analysis } \\
\hline prtT-F & GATCGTCGCAGAAATCCAAC \\
\hline prtT-R & TTCCAGCGTTCCAGATCTTC \\
\hline pep1-F & TGGCTATGTCTTCCCTTGCT \\
\hline pep1-R & TGACGGAAGCGTAGTTGATG \\
\hline aor1-F & CTCTGGGCAGCCATTGTATT \\
\hline aor1-R & TGGTGACTCAAGTGCTCCAT \\
\hline
\end{tabular}




\subsection{Characterization of the $\Delta$ prtT Knockout Mutants}

For growth assessment and sporulation quantification, PDA plates were inoculated centrally with $5 \mu \mathrm{L}$ of a conidia suspension $\left(10^{5}\right.$ conidia/mL $)$ of the P. digitatum parental strain Pd1, the ectopic prtT mutant, and two $\Delta p r t T$ knockout mutants. Cultures were incubated at $24^{\circ} \mathrm{C}$ for up to 7 days. Mycelial growth was determined by measuring two perpendicular diameters of the growing colonies at day 7 after inoculation. Sporulation assessment was carried out by scraping the surface of the 7-day-old cultures with a spatula. Conidia concentration was measured by using a haemocytometer.

Proteolytic activity on solid medium was assessed based on Ward [27]. Spores $\left(10^{5}\right.$ conidia/mL) were inoculated onto filter discs overlaid on solid complete medium plates (PDA) containing a colony restrictor ( $2 \mathrm{mg} / \mathrm{mL}$ dichloran). After 4 days of incubation at $24^{\circ} \mathrm{C}$, the filters were removed and the plates were overlaid with a layer of skim milk agarose ( $1 \%$ agarose, $1 \%$ skim milk, $0.45 \% \mathrm{CaCl}_{2}, 0.6 \%$ acetic acid, $\mathrm{pH}$ 5.5), and milk clotting was allowed to proceed at $37^{\circ} \mathrm{C}$ for 3 days. The extent of clotting was proportional to the number of proteases secreted by the colony that had occupied that position on the plate.

\subsection{Chemicals}

A protease inhibitor cocktail containing $1.4 \mathrm{mM}$ of trans-Epoxysuccinyl-L-leucylamido(4guanidino)butane (E-64), $500 \mathrm{mM}$ of 1,10-phenanthroline, $100 \mathrm{mM}$ of 4-(2-aminoethyl)benzenesulfonyl fluoride hydrochloride (AEBSF), and $2.2 \mathrm{mM}$ of pepstatin A was purchased from Sigma-Aldrich (P8215) (St. Louis, MO, USA). AEBSF, bestatin hydrochloride, E-64, phosphoramidon disodium salt, pepstatin A, ferrozine, diethyldithiocarbamate, and 1,10-phenanthroline hydrochloride monohydrate were also purchased from Sigma-Aldrich. Ethylenediaminetetraacetic acid calcium disodium salt dehydrate (EDTA) and dimethylsulfoxide (DMSO) were obtained from Applichem (Darmstadt, Germany).

\subsection{Orange Fruit Infection Assays}

To analyze the role of prtT in the pathogenicity of $P$. digitatum, we artificially inoculated the parental strain Pd1, one ectopic mutant (eprtT3), and two knockout mutants ( $\Delta$ prtT44 and $\Delta p r t T 70)$ on sweet oranges: 'Navelate' and 'Lane late' mature oranges that were obtained from a packinghouse in Lliria, Valencia (Spain) the same day of harvesting before receiving any postharvest treatment. They were brought to the laboratory, surface-disinfected with $5 \%$ sodium hypochlorite for $5 \mathrm{~min}$, rinsed with tap water, and allowed to dry. The next day, oranges were wounded four times around the equator with a nail ( $3 \mathrm{~mm}$ in depth) and were immediately inoculated by adding $10 \mu \mathrm{L}$ of a conidial suspension $\left(10^{4}\right.$ conidia/mL). Three replicates of five infected fruits with four wounds per fruit were placed on plastic boxes and incubated at $20^{\circ} \mathrm{C}$ and $90 \%$ relative humidity for 7 days. Disease incidence (measured as the percentage of infection) and severity (as maceration diameter, in $\mathrm{mm}$ ) were determined at day 5 and 7 post inoculation (dpi). Analysis of variance was performed to test the different incidence among strains at 5 dpi. Means were separated using the Tukey test with $p<0.05$, using Statgraphics Stratus (Statgraphics Technologies, Inc., The Plains, VA, USA).

To study the effect on virulence of either the protease inhibitor cocktail, its individual components, and other different protease inhibitors and chelators, P. digitatum conidia were artificially co-inoculated with the proteinase inhibitor cocktail, E-64, 1,10-phenanthroline, AEBSF, pepstatin A, the double or triple combination of the different components, and with bestatin, phosphoramidon, EDTA, EGTA, ferrozine, and DETC in mature oranges as described above. The assayed concentration of each compound is indicated in the figure legend. Incidence and severity were measured up to $7 \mathrm{dpi}$.

The effect of metals and the chelator 1,10-phenanthroline was assayed by co-inoculation of $10^{4}$ conidia/mL of P. digitatum $\mathrm{Pd} 1$ with different metal ions $\left(\mathrm{ZnSO}_{4}, \mathrm{CuSO}_{4}, \mathrm{MnSO}_{4}\right.$, and $\left.\mathrm{FeSO}_{4}\right)$ at $0.5 \mathrm{mM}$ either in the presence or absence of 1,10 -phenanthroline $0.5 \mathrm{mM}$ in mature oranges as described previously. Disease incidence was determined at 4, 5, and $6 \mathrm{dpi}$. 


\subsection{Gene Expression Analysis}

For RNA extraction, mature oranges were wounded using a nail and inoculated with $10 \mu \mathrm{L}$ of a conidial suspension $\left(10^{6}\right.$ conidia/mL, 16 wounds per fruit) from either the P. digitatum parental strain Pd1, the ectopic mutant (eprtT3), or a knockout mutant ( $\triangle$ prtT70). Inoculated fruits were stored at $20{ }^{\circ} \mathrm{C}$ and high humidity for 24,48 , and $72 \mathrm{~h}$. After each storage time, cylinders of peel containing the flavedo and the albedo of the fruit were removed using a cork borer of $5 \mathrm{~mm}$ centered in the inoculation point. Each biological replicate consisted of 80 discs (16 wounds per 5 fruits) and three biological replicates were collected at each sampling time point. All samples were immediately frozen in liquid nitrogen and then ground to a fine powder for subsequent RNA extraction. Spores of the parental strain, the ectopic mutant, and the knockout mutant were also frozen for subsequent RNA extraction.

Total RNA extraction from P. digitatum spores and from macerated orange peel tissue was done following a previously published protocol [28] with minor modifications. One gram of frozen tissue was extracted with $10 \mathrm{~mL}$ of RNA extraction buffer (100 mM Tris $\mathrm{HCl} \mathrm{pH}$ 8.0, $100 \mathrm{mM} \mathrm{LiCl}, 10 \mathrm{mM}$ EDTA pH 8.0, $1 \%$ SDS, $1 \%$ PVP-40, and 1\% $\beta$-mercaptoethanol). After phenol extraction, total nucleic acids were precipitated by adding one-tenth volume of $3 \mathrm{M}$ sodium acetate, $\mathrm{pH} 5.2$, and two volumes of cold ethanol, and incubating at $-20^{\circ} \mathrm{C}$ for at least $30 \mathrm{~min}$. For non-macerated orange peel tissue, RNA extraction was done according to López-Pérez et al. [21]. RNA concentration was measured spectrophotometrically. DNase treatment and first-strand cDNA synthesis were conducted with the Maxima H Minus cDNA synthesis kit with dsDNase (Thermo Scientific, Waltham, MA, USA) using $2 \mu \mathrm{g}$ of total RNA according to the manufacturer's instructions. RT-qPCR was conducted following the MIQE (Minimum Information for Publication of Quantitative Real-Time PCR Experiments) guidelines [29]. Gene-specific primer sets (Table 1) were designed for gene expression analysis with Primer3Plus [30]. Real-time qPCR reactions were performed in a LightCycler480 System (Roche Diagnostics, Basel, Switzerland) using SYBR Green to monitor cDNA amplification. Gene expression measurements were derived from three biological replicates and two technical replicates. Relative gene expression (RGE) was calculated using the formula described by Pfaffl [26]. For each primer pair and each sample, the PCR efficiency (E) and the quantification cycle (Cq) were assessed using LinRegPCR software version 2017.1. Amplicon specificity was examined by analysis of the melting curve. The Cq value for the reference normalization factor (REF) was calculated by taking actin (PDIP_18200) as the reference gene, using primer pairs PdACTFor2/PdACTRev2 [21].

\section{Results}

\subsection{Identification of a prtT Ortholog in P. digitatum and Construction of Knockout Mutants}

In order to identify a PrtT homolog in P. digitatum, we interrogated the automatically annotated P. digitatum genome sequence available at the NCBI (National Center for Biotechnology Information) [18]. A BlastP search was performed using the sequence of PrtT from A. niger (XP_001402055.1) as a query. PDIP_25240 was the protein with the highest identity, 52\%, regularly distributed along the whole sequence, although it missed about 300 aa at the $\mathrm{N}$-terminus that were present in A. niger PrtT. The original automatic annotation of PDIP_25240 corresponded to a protein with 368 aa, much shorter than A. niger PrtT, which contains 623 aa. A more detailed examination of the P. digitatum Pd1 locus allowed the reannotation of the $p r t T$ gene, which contains five exons, as its $A$. niger prt $T$ counterpart, and codes for a protein with 636 aa. Multiple sequence alignment of $P$. digitatum PrtT with orthologues from other Aspergillus and Penicillium species showed that they all contained the fungal-specific $\mathrm{Zn}_{2} \mathrm{Cys}_{6}$ binuclear DNA binding cluster domain, conserved in both genera (Figure 1A) [14]. The identities of P. digitatum PrtT (636 aa) with the amino acid sequences of PrtT from Penicillium rubens (GenBank accession number XP_002565177), P. oxalicum (EPS29021), A. niger (XP_001402055), and A. fumigatus (KEY83531) were $89 \%, 63 \%, 52 \%$, and 50\%, in 637, 629, 616, and 613 amino acids, respectively. 
A

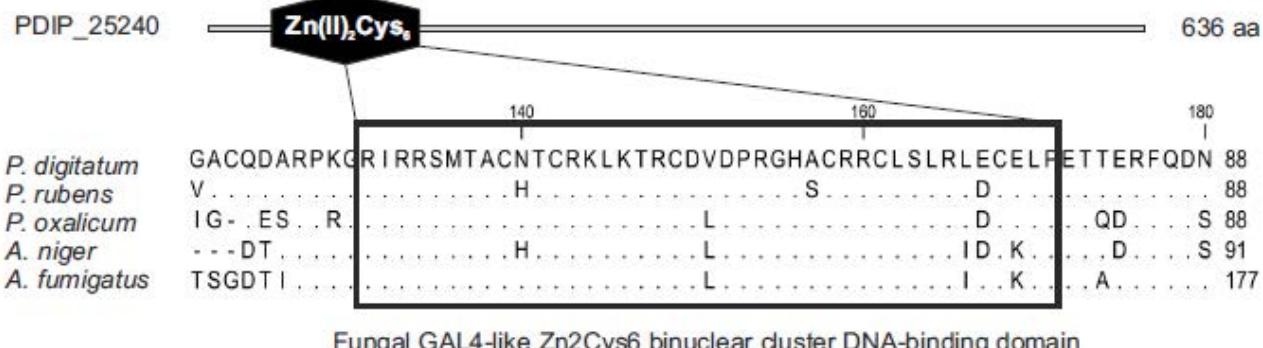

B
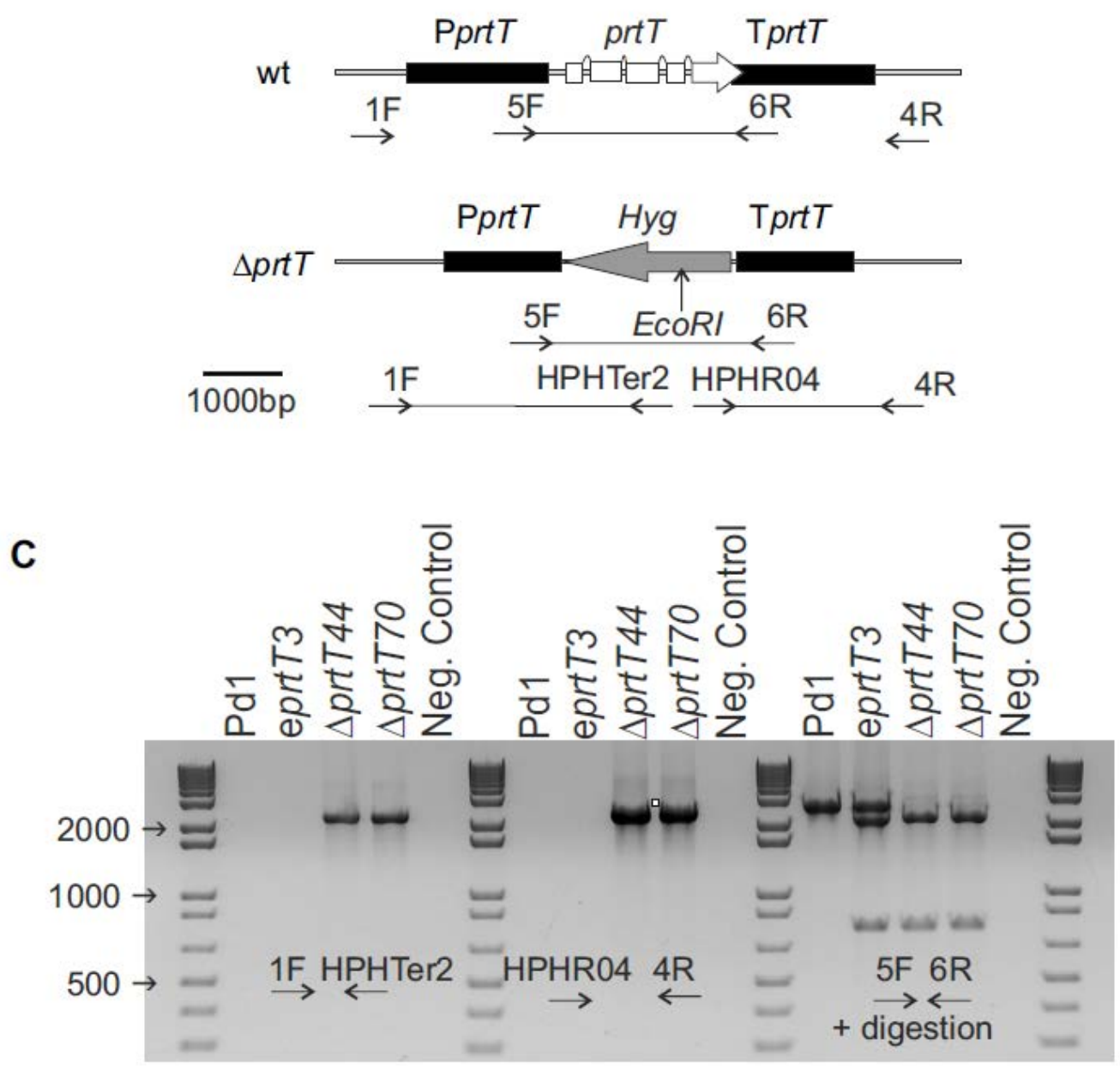

Figure 1. Deletion of Penicillium digitatum prtT. (A) A fungal-specific $\mathrm{Zn}_{2} \mathrm{Cys}_{6}$ binuclear DNA binding cluster (black box) located at the N-terminal region of P. digitatum PrtT. The GeneBank accession number of aligned homologs are as follows: Penicillium rubens Wisconsin 54-1255 (XP_002565177), Penicillium oxalicum 114-2 (EPS29021), Aspergillus niger CBS 513.88 (XP_001402055.1), and Aspergillus fumigatus var. RP-2014 (KEY83531). Identical amino acids are indicated by a dot ' $\because$. (B) Diagram of the wild type P. digitatum Pd1 and deleted prtT loci, including the diagnostic primers used for checking the deletion (see also Table 1). PprtT: P. digitatum prtT gene promoter; TprtT: P. digitatum prtT gene terminator; Hyg; hygromycin resistance gene. (C) Polymerase chain reaction amplification of the wild type Pd1, the ectopic eprtT3 mutants, and the two knockout $\Delta p r t T 44$ and $\Delta p r t 770$ mutants with diagnostic primers. 
Targeted gene disruption of prtT using the methodology previously described [18] was performed to investigate the role of the encoded protein in the pathogenicity of P. digitatum. The first step of the gene deletion strategy was to construct the plasmid pDprtT using the USER-friendly cloning technique. Positive E. coli transformants were selected as kanamycin-resistant colonies and screened by PCR (data not shown). Afterward, the plasmid was introduced into electrocompetent $A$. tumefaciens AGL1 cells. The following step was the transformation of $P$. digitatum by co-cultivation with A. tumefaciens. Putative transformants were selected in the presence of hygromycin B.

The correct deletion of the prtT gene was verified by PCR using the primers 1F/HPHTer2 for the identification of the integration at the promoter region, and HPHPRO4/4R for the terminator region (Table 1 and Figure 1B). Figure 1C shows the expected band pattern for both knockout $\Delta p r t T 44$ and $\Delta$ prtT70 mutants, not observed in the parental strain Pd1 or the ectopic eprtT3 mutant. The confirmation of the presence/absence of the $\operatorname{prt} T$ gene was also observed using primers $5 \mathrm{~F} / 6 \mathrm{R}$, which flanks the coding region of the $p r t T$ gene, after digestion of the PCR amplification product with EcoRI. A DNA fragment of $2700 \mathrm{bp}$ corresponding to the prtT gene was observed in the parental strain, whilst two fragments of 2150 and $750 \mathrm{bp}$ corresponding to the replacement of the $\operatorname{prtT}$ gene by the hygromycin-resistance gene were observed in both knockout mutants. Thus, the hygromycin-resistance marker was integrated by double homologous recombination replacing the prtT gene, whereas the ectopic transformant eprtT3 showed the three bands. The number of T-DNA copies integrated into the genome of each transformant was assessed by qPCR analysis, confirming that the knockout mutants contained a single T-DNA integration (Table 2).

Table 2. Estimation of the number of T-DNA copies that have been integrated into the genome of the mutants.

\begin{tabular}{ccccccc}
\hline Strain & Genotype & Cq prtT & Cq Actin & $\Delta$ Cq Target & sCq Actin & $\begin{array}{c}\text { Copy } \\
\text { Number }\end{array}$ \\
\hline Pd1 & wild type & $23.9 \pm 0.0$ & $22.1 \pm 0.1$ & 0.0 & 0.0 & - \\
eprtT3 & ectopic & $23.6 \pm 0.0$ & $24.9 \pm 0.2$ & 0.3 & -2.8 & 6.7 \\
$\Delta$ prtT44 & knockout & $23.8 \pm 0.1$ & $22.2 \pm 0.1$ & 0.1 & -0.1 & 1.1 \\
$\Delta$ prtT70 & knockout & $24.5 \pm 0.1$ & $22.7 \pm 0.2$ & -0.6 & 0.0 & 0.7 \\
\hline
\end{tabular}

\subsection{Characterization of P. digitatum $\Delta$ prtT Knockout Mutants}

Conidia production of the parental strain Pd1, ectopic, and $\Delta p r t T$ knockout mutants were assessed on PDA plates after 7 days of incubation. Fungal growth was assayed by measuring two perpendicular diameters of at least five independent colonies up to 7 days post inoculation, when conidia were collected to determine conidia production (Figure 2A). No differences were observed in colony growth among different strains (data not shown). The parental strain and the two knockout mutants produced a similar amount of conidia per colony area (approximately 215,000 conidia/ $\mathrm{mm}^{2}$ ), whereas the ectopic mutant had the highest production (approximately 290,000 conidia $/ \mathrm{mm}^{2}$ ).

Based on the hypothesis that the prtT deletion mutant should be impaired in the production of extracellular proteases, a protein degradation assay was performed with the four strains in solid culture medium. We inoculated the strains onto filter discs on PDA plates containing $2 \mathrm{mg} / \mathrm{mL}$ of dichloran to restrict colony growth. After growth of the colonies during 4 days at $24{ }^{\circ} \mathrm{C}$, the filters were removed and the plates were overlaid with a layer of agarose containing skim milk. Hydrolysis of milk proteins, mostly casein, at $37^{\circ} \mathrm{C}$ during 3 days led to the appearance of a proteolytic halo. A clearing zone was observed only with strains expressing the $\operatorname{prtT}$ gene: The parental strain Pd1 and the ectopic mutant (Figure 2B). No halo, or a very thin halo, was observed in both knockout mutants, indicating that no or poor proteolysis took place. 
A

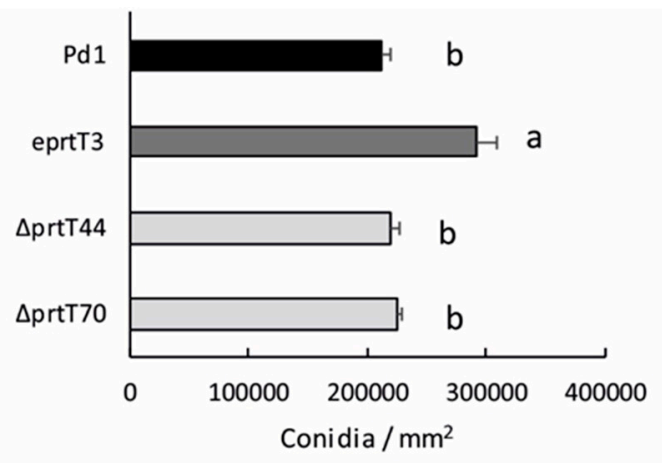

B

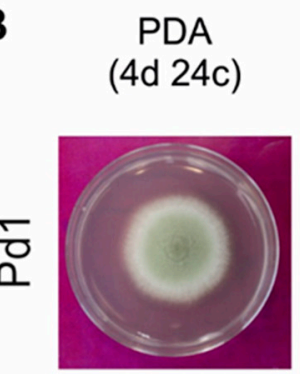

PDA+dichloran PDA+dichloran

$(4 \mathrm{~d} 24 \mathrm{c})$

$(4 \mathrm{~d} 24 \mathrm{c})$

+ layer $(3 d 37 c)$
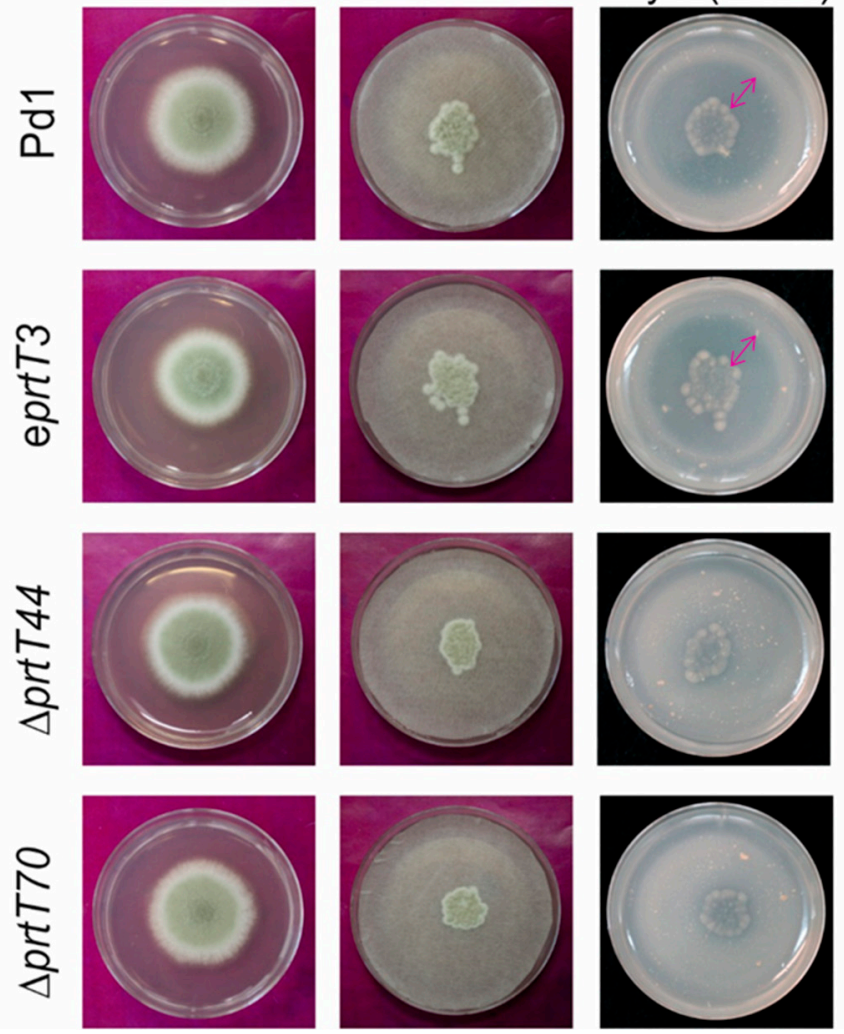

Figure 2. Phenotypic analysis of the $\Delta p r t T$ mutants. (A) Conidia production per colony area (in $\mathrm{mm}^{2}$ ) of the parental strain Pd1, the ectopic eprtT3 mutant, and the two knockout mutants $\Delta p r t T 44$ and $\triangle p r t T 70$. Strains were grown on PDA plates and the conidia were collected and countered after 7 days at $24{ }^{\circ} \mathrm{C}$. Error bars indicate the standard deviation of at least three biological replicates. Different letters indicate statistically significant differences among strains at $p<0.05$. (B) Colony view of the parental strain Pd1, the ectopic eprtT3 mutant, and the two knockout $\Delta p r t T 44$ and $\Delta p r t T 70$ mutants after growing on PDA during 4 days at $24^{\circ} \mathrm{C}$, or on PDA containing dichloran during 4 days at $24^{\circ} \mathrm{C}$, or on PDA + dichloran during 4 days at $24^{\circ} \mathrm{C}$ followed by a 3 day incubation at $37^{\circ} \mathrm{C}$ after adding an agarose layer containing skim milk. The $\Delta p r t T$ mutants formed a reduced proteolytic halo (indicated with an arrow) on skim milk media.

\subsection{The P. digitatum $\Delta$ prtT Mutants Are Not Altered in Virulence}

To test the role of PrtT in the pathogenicity of P. digitatum, the virulence of the parental strain Pd1, the ectopic eprtT3 mutants and the two knockout $\Delta p r t T 44$ and $\Delta p r t T 70$ mutants was tested. We inoculated 
'Navelate' (Figure 3A,B) and 'Lane late' (Figure 3C-F) sweet oranges in three independent experiments and measured the incidence (percentage of infection) and the disease severity (measured as the diameter of the macerated tissue) at 5 and 6 to 7 days post inoculation in three independent infection assays. The incidence and severity results showed that the knockout mutants were as virulent as the parental strain Pd1 in all three experiments. Only in one out of the three independent replicates (experiment 2, Figure $3 C, D$ ) was the incidence and maceration diameter lower in the ectopic mutant compared to the parental strain and the two knockout mutants. The multifactor analysis of variance at $5 \mathrm{dpi}$ to test the significant interactions amongst the factors showed that there was not a difference among the fungal incidence of the four samples ( $p$-value $=0.2291$ ), but there was a statistical significance depending on the date of the experiment at the $95 \%$ confidence level $(p$-value $=0.0000)$.

A

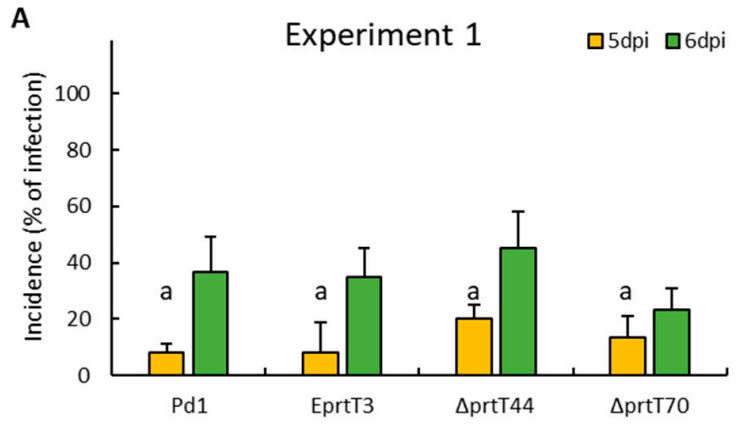

C

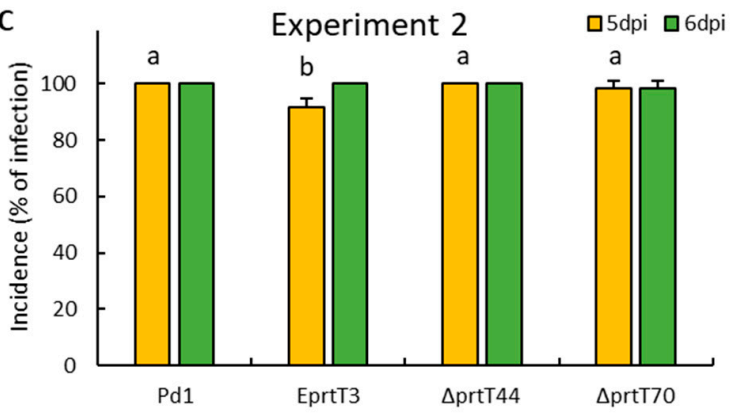

E

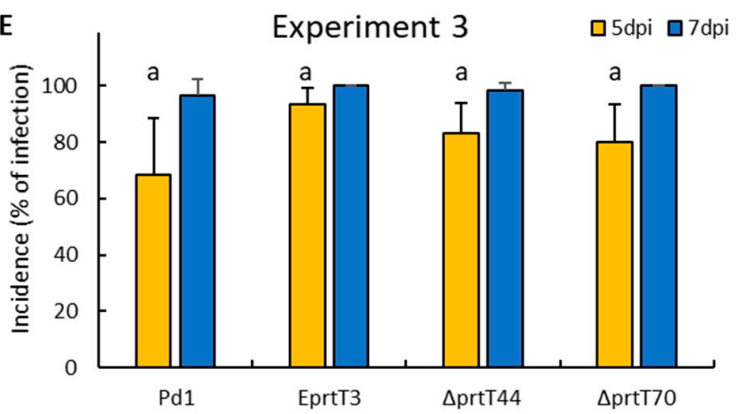

B

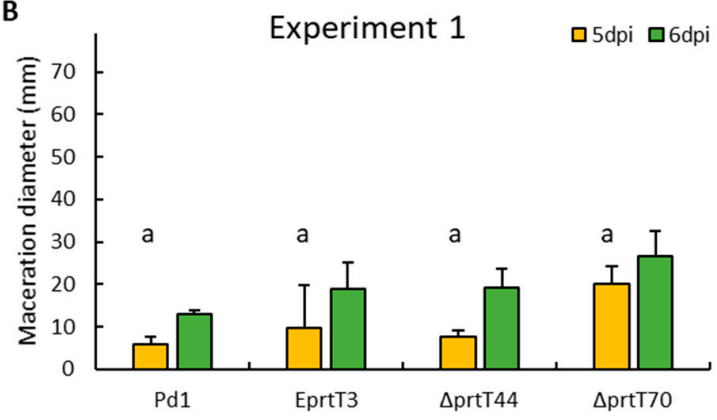

D

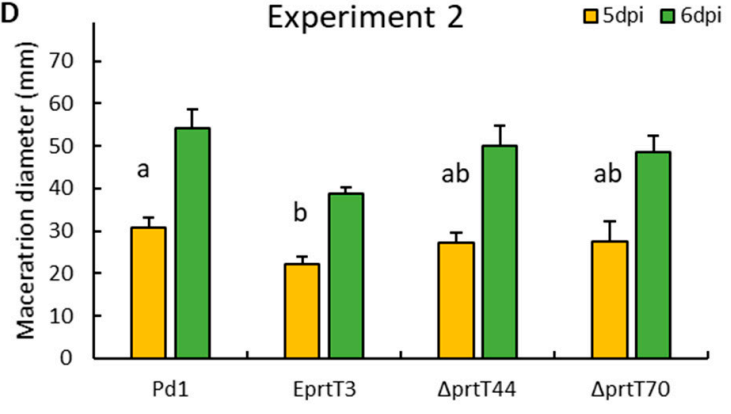

$\mathbf{F}$

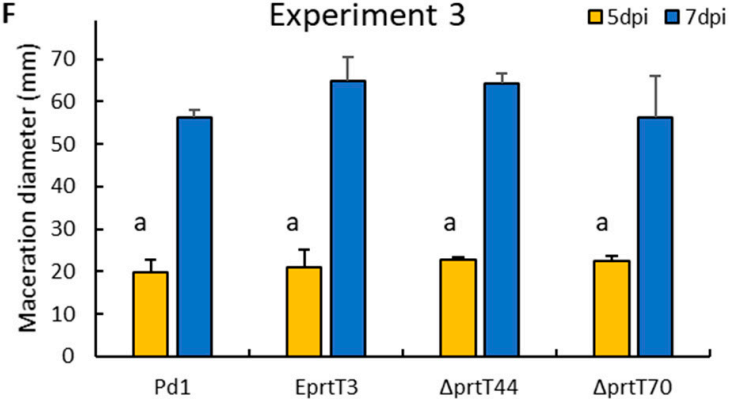

Figure 3. Three independent virulence assays of $P$. digitatum strain Pd1, the ectopic eprtT3 mutant, and the two knockout $\Delta p r t T 44$ and $\Delta p r t T 70$ mutants towards citrus fruit. Navelate $(\mathbf{A}, \mathbf{B})$ and Lane late (C-F) oranges were wounded and inoculated with $10 \mu \mathrm{L}$ of a spore suspension $\left(10^{4} \mathrm{conidia} / \mathrm{mL}\right)$ of the different strains. Fruits were incubated at $20{ }^{\circ} \mathrm{C}$ and $90 \%$ relative humidity for up to 7 days. There were three replicates of five fruits and four wounds per fruit. Bars show the mean values of the incidence as the percentage of infected wounds $(\mathbf{A}, \mathbf{C}, \mathbf{E})$ and the maceration diameter in $\mathrm{mm}(\mathbf{B}, \mathbf{D}, \mathbf{F})$, and their standard deviations at 5 and 6 to 7 days post-inoculation (dpi). Bars labeled with the same letter at 5 dpi do not differ at the $95 \%$ confidence level based on the Tukey's test. 


\subsection{PrtT Has Only a Minor Effect on the Expression of the Two Major Proteases during Infection}

Previous results showed that genes coding for fungal proteases, plant cell-wall related enzymes, redox homeostasis, and detoxification processes were the major categories induced during the infection of citrus fruit by P. digitatum [21]. The most represented gene in the subtracted cDNA library was PDIP_82060 (denoted as pep1), which codes for a putative aspartic endopeptidase Pep1. In the same study, other genes coding for putative proteases/peptidases were also detected: An aspergillopepsin (PDIP_06020), a tripeptidyl peptidase (aor1; PDIP_12220), a carboxypeptidase (PDIP_71590), and a serine peptidase (PDIP_67670). According to SignalIP prediction (http://www.cbs.dtu.dk/services/SignalP/), four of them, except the serine peptidase, are extracellular proteases. As it was evident from the proteolytic assay that PrtT regulates the production of different extracellular proteases, we monitored the transcript levels of the prtT gene and the genes that encode the two major secreted proteases of P. digitatum during the infection process (PDIP_82060 and PDIP_12220). For this study, we collected spores and peel tissue of oranges infected with the parental strain Pd1, the ectopic eprtT3 mutant, and the knockout mutant $\Delta p r t T 70$, at 12, 24, 48, and 72 hours post inoculation (hpi). A similar pattern of expression for prtT (PDIP_25240) was observed in both the parental strain Pd1 and the ectopic mutant (Figure 4A), showing the highest levels of expression in the spores. Expression of $\operatorname{prtT}$ decreased abruptly just during spore germination and remained very low during the infection process. As it was expected, no amplification of this gene was observed in the $\Delta p r t T 70$ knockout mutant at any time point (Figure 4A). Results of the time-course experiment showed that both the putative aspartic endopeptidase pep1 (PDIP_82060, Figure 4B) and the tripeptidyl peptidase aor1 (PDIP_12220, Figure 4C) encoding genes showed a similar pattern of expression during the development of Pd1 in oranges, with the higher levels of expression of the gene encoding the aspartic endopeptidase. For both genes, maximum expression was observed at $48 \mathrm{hpi}$ and, thereafter, its expression decreased. The expression of the two protease-encoding genes in the ectopic eprtT3 and the $\Delta$ prtT70 knockout mutant followed a pattern similar to that found in the parental strain, with maximum expression at 48 to $72 \mathrm{hpi}$. The differences were in the expression levels, which were lower in the knockout mutant.

\subsection{Application of Protease Inhibitors Reduced the Virulence of P. digitatum in Citrus Fruit}

In order to study the effect of different protease inhibitors on virulence, we co-inoculated citrus fruits with P. digitatum strain Pd1 conidia and a cocktail containing different protease inhibitors. Disease incidence and severity were determined up to $6 \mathrm{dpi}$. Results showed that the protease inhibitor cocktail at $1 \%$ was very effective (Figure 5), resulting in no visible disease development for up to 6 days, when the control fruits reached $98.3 \%$ infection by day 5 . Even when applied at $0.1 \%$, disease development was reduced by $66 \%$ at $5 \mathrm{dpi}$. This protection was not due to the presence of DMSO, the solvent used to prepare the cocktail, as disease development was not affected by the solvent at the final concentrations present in the co-inoculation mixtures. The components of the cocktail were $100 \mathrm{mM}$ AEBSF (a serine protease inhibitor), $500 \mathrm{mM}$ 1,10-phenanthroline (a metalloprotease inhibitor), $2.2 \mathrm{mM}$ pepstatin A (a specific inhibitor of aspartyl proteases), and 1.4 mM E-64 (a broad-spectrum cysteine-protease inhibitor). We then conducted infection assays with the individual inhibitors at two different conidia concentrations, $10^{4}$ and $10^{5}$ conidia/mL (Figure $5 \mathrm{~A}, \mathrm{~B}$ ). Disease incidence of P. digitatum in artificially inoculated oranges was $96.7 \%$ and $100 \%$ after 5 dpi with $10^{4}$ and $10^{5}$ conidia/mL, respectively (Figure 5A,B). Similar results were observed with the co-inoculation of P. digitatum with the individual inhibitors, E-64, AEBSF, and pepstatin A. However, a complete absence of disease development up to 6 days was observed when P. digitatum was co-inoculated with either $1 \%$ cocktail or $10 \mathrm{mM}$ 1,10-phenanthroline. These results clearly showed that 1,10-phenanthroline was the inhibitor with a major role inhibiting disease development. To further evaluate the possible interaction of 1,10-phenanthroline with the other inhibitors present in the cocktail, we co-inoculated P. digitatum with all possible combinations of the four protease inhibitors (Figure 5C,D). Our results showed that only the mixtures containing 1,10-phenanthroline were able to control the infection of Pd1 in 
oranges, confirming that this compound was responsible for the reduction of the P. digitatum infection in citrus fruit.

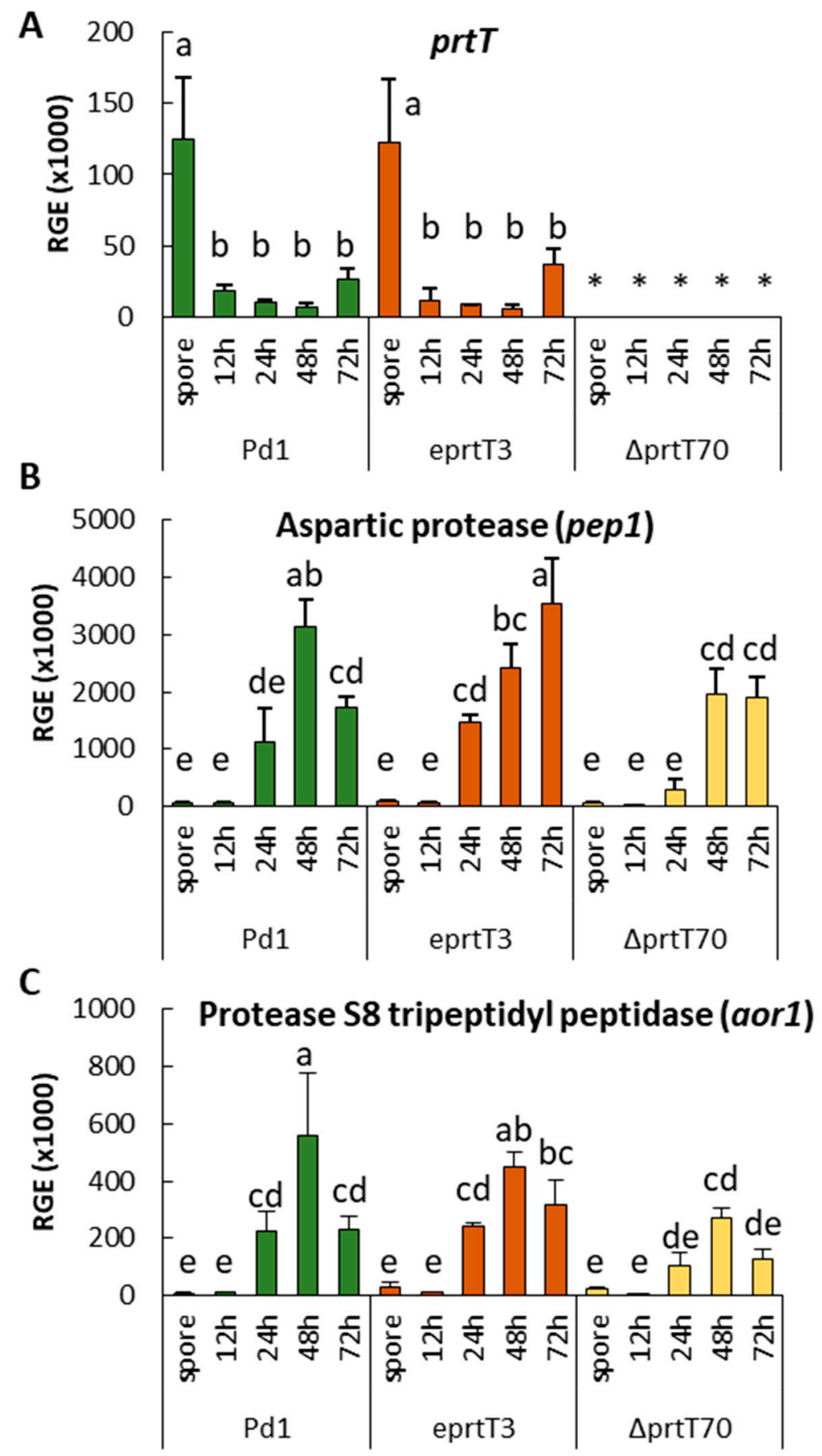

Figure 4. Analysis of normalized in vivo relative gene expression (RGE) in P. digitatum strain Pd1 (green bars), the ectopic eprtT3 mutant (orange bars), and the knockout $\Delta p r t T 70$ mutant (yellow bars). The analysis was carried out in spores and at 12, 24, 48, and 72 hours after inoculation of orange fruits with the different strains. Bars show the mean values of three biological replicates and their standard deviations. The gene expression is relative to the P. digitatum actin gene as a reference. (A) PDIP_25240: Transcriptional activator of proteases, prtT; (B) PDIP_82060: aspartic protease, pep1; and (C) PDIP_12220: putative protease S8 tripeptidyl peptidase I, aor1. Bars labeled with the same letter indicate that there are no statistically significant differences at the $95 \%$ confidence level based on the Tukey's test. The asterisk * indicates no expression level detected under the tested conditions. 

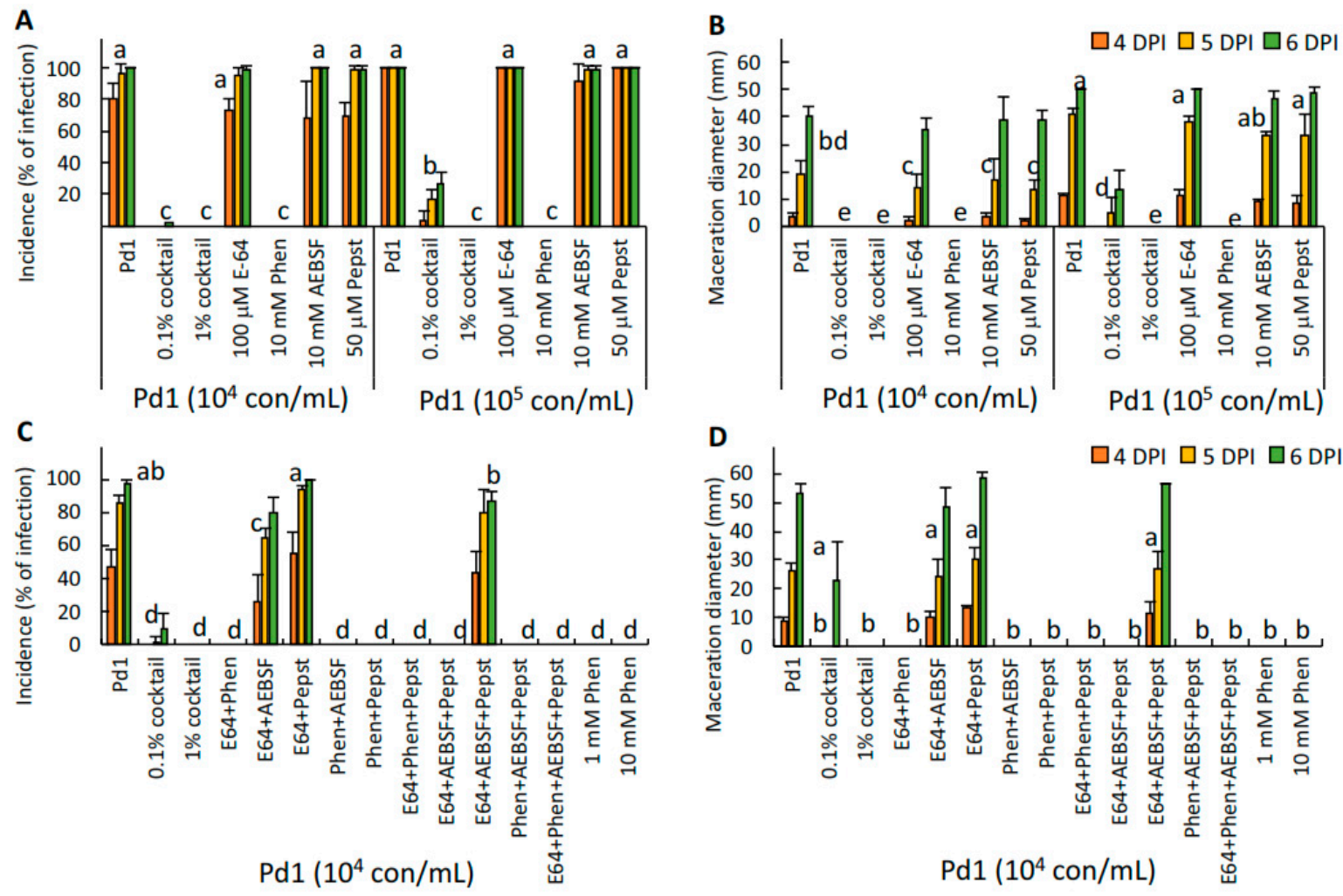

Figure 5. Disease incidence (percentage of infection, $\mathbf{A}$ and $\mathbf{C}$ ) and severity (maceration diameter, in $\mathrm{mm}, \mathbf{B}$ and D) caused by $P$. digitatum strain Pd1 in artificially inoculated oranges in two independent experiments (experiment 1: A and B; experiment 2: $\mathbf{C}$ and D) after 4, 5, and 6 days post infection (dpi). Conidia were co-inoculated with the proteinase inhibitors in a final volume of $10 \mu \mathrm{L}$ containing the cocktail of proteinase inhibitor cocktail at either $0.1 \%$ or $1 \%, 100 \mu \mathrm{M} \mathrm{E}-64,1$ or $10 \mathrm{mM} 1,10$-phenanthroline (Phen), $10 \mathrm{mM}$ 4-(2-Aminoethyl)benzenesulfonyl fluoride hydrochloride (AEBSF), or $50 \mu \mathrm{M}$ pepstatin A (Pep). Means with the same letter are not significantly different $(p<0.05)$ at 5 dpi according to Tukey's test.

\subsection{Application of Metalloproteinase Inhibitors and Chelators}

Previous results have shown that 1,10-phenanthroline was the compound involved in the reduction of $P$. digitatum infection in mature orange fruits. It is known that this compound is an inhibitor of metalloproteases by removal and chelation of the metal ions required for enzyme activity. In order to study the effect of other metalloprotease inhibitors and chelators in the pathogenicity of P. digitatum, we co-inoculated the fungus with different known inhibitors and chelators: 1,10-phenanthroline, bestatin (an aminopeptidase inhibitor), phosphoramidon (a metalloendopeptidase inhibitor), and the metal ion chelators EDTA, EGTA, ferrozine, and DETC (Figure 6A). Neither protease inhibitors, bestatin or phosphoramidon, nor EGTA, DETC, or ferrozine reduced significantly the percentage of infection of P. digitatum compared to the parental strain Pd1, with EDTA being the only chelator that significantly reduced disease development. Only the co-inoculation of Pd1 with 1,10-phenanthroline completely prevented the development of the fungus in the oranges.

To test the hypothesis that the activity of 1,10-phenanthroline is related to the chelation of metal ions, we co-inoculated P. digitatum $\mathrm{Pd} 1$ with four different metal ions $\left(\mathrm{ZnSO}_{4}, \mathrm{CuSO}_{4}, \mathrm{MnSO}_{4}\right.$, and $\left.\mathrm{FeSO}_{4}\right)$ either alone or in the presence of 1,10-phenanthroline (Figure 6B). The co-inoculation of P. digitatum with the four different metal ions did not deter the development of the pathogen; however, as we indicated previously, the application of 1,10-phenanthroline substantially reduced disease incidence. The combined application of 1,10-phenanthroline with $\mathrm{CuSO}_{4}$ partially reverted the effect of the protease inhibitor, and only the application of $\mathrm{ZnSO}_{4}$ and $\mathrm{FeSO}_{4}$ together with 1,10-phenanthroline totally 
reverted the effect of the tested protease inhibitor, confirming the hypothesis that 1,10-phenanthroline acts by chelating metal ions that are necessary for the development of P. digitatum in oranges.
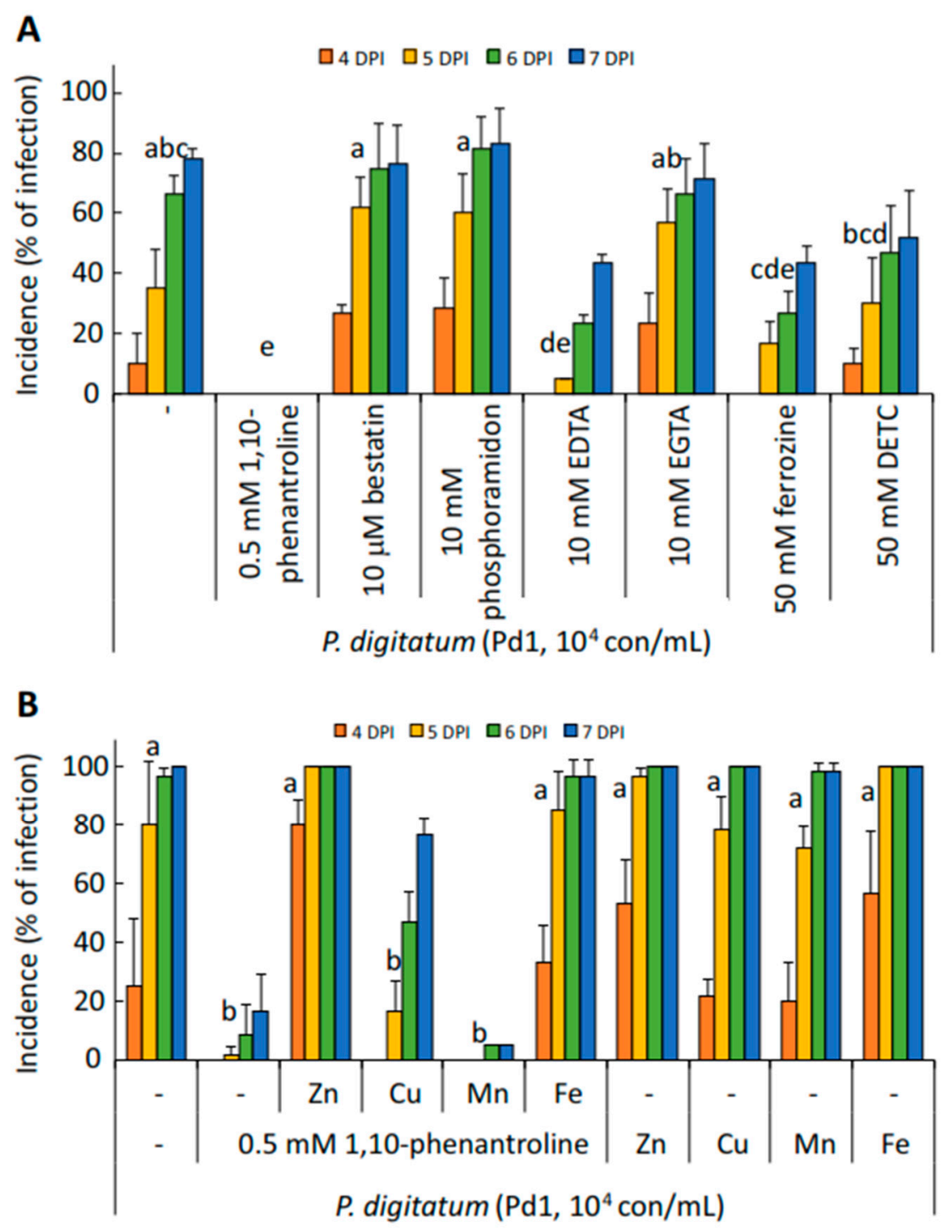

Figure 6. (A) Disease incidence (percentage of infection) caused by P. digitatum strain Pd1 in artificially inoculated oranges after 4, 5, 6, and 7 days post infection (dpi). Conidia were co-inoculated with different metalloproteinase inhibitors and chelators. (B) Disease incidence caused by P. digitatum Pd1 co-inoculated with different metal ions $\left(\mathrm{ZnSO}_{4}, \mathrm{CuSO}_{4}, \mathrm{MnSO}_{4}\right.$, and $\mathrm{FeSO}_{4}$ at $\left.0.5 \mathrm{mM}\right)$ in the presence or absence of $0.5 \mathrm{mM}$ of 1,10-phenanthroline in mature orange fruit. Means with the same letter are not significantly different $(p<0.05)$ at 5 dpi according to the Tukey's test.

\section{Discussion}

This study aimed to characterize the role of secreted proteases in the virulence of P. digitatum towards citrus fruit. Because most of the protease-encoding genes belong to gene families containing an elevated number of members, it is not technically feasible to delete more than a few of these genes at a time. This methodology has been described in B. cinerea by constructing single and double knockout mutants of five members from an aspartic proteinase gene family; however, the role of them in the virulence is not completely clear [12]. In our study, instead of simultaneously deleting several $P$. digitatum protease genes at a time, we designed two alternative approaches to determine the contribution of secreted proteolytic activities to the virulence of P. digitatum: (i) Construction of prtT 
knockout mutants and characterization of the mutants during in vitro and in vivo growth, and (ii) the application of different protease inhibitors during the infection of $P$. digitatum in sweet oranges.

As a first approach, we focused on the P. digitatum prtT gene, which encodes a putative transcription factor controlling the expression of multiple secreted proteases. The disruption of the $\operatorname{prt} T$ gene has been previously described in A. niger [13], A. fumigatus [14-16,31], and P. oxalicum [17]. As far as we are aware, there are no reports on the possible role of secreted proteases in the virulence of fungal pathogens of citrus fruit. Characterization of two independent knockout mutants revealed that PrtT is required for the production of several extracellular proteases by P. digitatum (Figure 2B). However, the absence of the regulator has just a small influence on the expression of the genes encoding the major putative extracellular proteases secreted by $P$. digitatum during the infection of sweet oranges (Figure 4) and has no effect in the virulence of the fungus (Figure 3).

Secreted protease activity depends on the $\mathrm{pH}$ of the growth media and the nitrogen or carbon source, among others [2]. For example, in A. fumigatus, protease activity was repressed by ammonia, or elevated $\mathrm{pH}$, and activated in the presence of proteins as the sole nitrogen source [16]. In the present study, conidia production per area of growth of the P. digitatum $\Delta p r t T$ knockout mutants were similar to those of the parental strain under the tested conditions (Figure 2A). It has been described that proteases constitute the largest group of $P$. digitatum genes up-regulated during the infection of oranges and that they might contribute to pathogenicity in different ways, such as degrading plant cell components or inactivating defense proteins [21]. We have shown that the protease activity of the $\Delta p r t T$ knockout mutants grown on PDA and further incubated with skim milk was reduced to almost undetectable levels (Figure 2B) with respect to the parental strain and the ectopic mutant. This result indicates that PrtT is involved in the regulation of at least some proteases that are required by P. digitatum to degrade skim milk when the fungus grows on PDA medium. However, whether PrtT is involved in the regulation of additional proteases would require further experiments.

In order to determine the role of PrtT in virulence, the knockout $\Delta p r t T 70$ mutant, the ectopic mutant, and the parental strain P. digitatum were artificially inoculated in sweet oranges (Figure 3). After 7 days of inoculation, no significant differences were observed in the incidence and the maceration diameter among them, suggesting that PrtT is not involved in the virulence of this postharvest pathogen in citrus fruit. Similar results have been previously observed in A. fumigatus, in which the prtT gene appears not to be essential for pathogenicity in animal models [14,16,31]. The A. fumigatus $\Delta$ prtT mutant showed reduced killing of lung alveolar cells and erythrocyte lysis [14,16]; however, the mutant strain showed wild-type virulence in infected neutropenic mice, suggesting that perhaps residual protease activity was sufficient to enable virulence $[14,16]$. Our results suggest that although PrtT regulates a group of secreted proteases (Figure 2B), it has no role in virulence (Figure 3). As already pointed out in the work done with $A$. fumigatus PrtT, this result could suggest that either residual protease activity is sufficient to enable virulence or that proteases are dispensable for pathogenicity in this fungus $[14,16]$. Another possible explanation is that the major extracellular proteases secreted by the pathogen during the infection process are not regulated by the prtT gene. To test this hypothesis, we analyzed the expression of the two genes coding for the major putative proteases during the P. digitatum infection process: The aspartic endopeptidase pep1 encoding gene (PDIP_25240) and the tripeptidyl peptidase aor1 encoding gene (PDIP_12220) [21]. The expression of these two genes during the infection of oranges was barely affected by the loss of the prt $T$ gene, indicating that the regulation of these genes depends mostly on another factor(s). XprG is another transcription factor that regulates extracellular protease production in Aspergillus nidulans, a fungus that lacks a PrtT homolog. Deletion of both A. fumigatus xprG and prtT genes resulted in the generation of a mutant with almost no ability to degrade proteins; however, it retained wild-type virulence in murine systemic and pulmonary models of infection [31]. In the case of P. digitatum, we identified a single XprG ortholog by amino-acid similarity to A. fumigatus XrpG (data not showed). The possibility that these two major proteinases are relevant for $P$. digitatum virulence in sweet oranges and the role of XrpG in the regulation of protease secretion should be further explored. In future experiments, we might generate P. digitatum 
deletion mutants in these two genes encoding major extracellular proteases and in the $x r p G$ putative transcription factor gene.

In the second approach, we investigated the effect of the application of different protease inhibitors on the virulence of $P$. digitatum. The presence of protease inhibitors has been described in plants and they are part of the pathogenesis-related proteins [32]. The first protease inhibitor proteins, trypsin and chymotrypsin inhibitors, with antifungal activity were described in Brassica oleracea by Lorito et al. [33], and subsequently, other protease-inhibitor proteins, such as cystatin, have been described in plants [34-37]. In the present study, we investigated the role of different protease inhibitors on the virulence of $P$. digitatum in oranges, and after 6 days post-inoculation, only 1,10-phenanthroline and the combinations containing this metalloprotease inhibitor were effective in controlling the development of P. digitatum in oranges. We tested other metalloprotease inhibitors, such as bestatin and phosphoramidon, and different metal ion chelators, such as EDTA, EGTA, ferrozine, and DETC (Figure 6A); although none of them were as effective as 1,10-phenanthroline in reducing the development of $P$. digitatum in citrus fruit, we observed some protective effect with some chelators, specially EDTA.

1,10-phenanthroline is a membrane permeable heterocyclic compound with the ability to sequester metal ions in biological systems, forming coordination compounds with them [38]. It has the capability of inhibiting the biological role of metal-dependent proteins, interfering with metal acquisition, bioavailability, and metabolism for crucial reactions; disturbing the microbial cell homeostasis; and culminating in the blockage of microbial nutrition, growth, development, and playing an important role in the in vivo infection progression [39]. The utilization of metal complexes containing 1,10-phenanthroline as antimicrobials against a broad spectrum of bacteria and as a potential alternative to antibiotics has been described previously [39]. Phenanthroline-based complexes can penetrate the cell membrane and can interact with relevant biomolecules in the microorganisms, leading to inhibition of the cell growth and causing cell death, exhibiting a broad spectrum of both antibacterial (e.g., against E. coli and Pseudomonas aeruginosa) and antifungal (e.g., against $A$. niger and Fusarium solani) activities. Metal sequestration is also found in nature as a means to combat microbial infection. The process by which a host organism sequesters trace minerals in an effort to limit pathogenicity during infection has been designated 'nutritional immunity' [40-42]. Well-studied examples of nutritional immunity include the production of the iron binding lactoferrin or the zinc and manganese binding protein calprotectin [40-42]. The antimicrobial activity of these proteins is mostly due to their capability to bind metal ions, as is the case of siderophores secreted by many biocontrol microbial antagonists $[43,44]$. Moreover, it has been hypothesized that the high level of gluconic acid secretion found during pathogenicity of apple fruits by P. expansum could be involved in the formation of iron chelates, which could favor iron acquisition and pathogenicity [45].

In the present work, we co-inoculated P. digitatum with some metal ions $\left(\mathrm{ZnSO}_{4}, \mathrm{CuSO}_{4}, \mathrm{MnSO}_{4}\right.$, and $\mathrm{FeSO}_{4}$ ) in sweet oranges to further analyze the role of 1,10-phernatroline as a metalloproteinase inhibitor and as a chelator. We chose these four metal ions because 1,10-phenanthroline has a very high affinity for $\mathrm{Fe}^{2+}, \mathrm{Zn}^{2+}$, and $\mathrm{Cu}^{2+}$, but very low affinity for $\mathrm{Mn}^{2+}$. We hypothesized that the effect of these metal ions reverting the inhibition of 1,10-phenanthhroline would be related to their affinity to this chelator. The co-inoculation had no effect in the development of the pathogen, with an incidence of $100 \%$ of infected wounds after $7 \mathrm{dpi}$ (Figure 6B). However, as indicated previously, the application of 1,10-phenanthroline drastically reduced the growth of the fungal pathogen in the fruit. The application of a plant protease inhibitor as an antifungal agent has been evidenced in transgenic rice constitutively expressing a potato carboxypeptidase inhibitor; these plants exhibit resistance against the economically important pathogens, Magnaporthe oryzae and Fusarium verticillioides [46]. The effect of 1,10-phenanthroline preventing the infection of citrus fruit by P. digitatum was partially reverted by application of $\mathrm{CuSO}_{4}$, and was completely reverted by the addition of $\mathrm{ZnSO}_{4}$ and $\mathrm{FeSO}_{4}$ (Figure 6B), indicating that the fungus is most susceptible to zinc and iron and, to a lesser extent, copper deprivation during the infection process. The concept of fungal micronutrient scavenging can be used 
in future studies aimed at developing a product containing a chelator, such as 1,10-phenanthroline, capable of reducing the development of fungal pathogens during postharvest.

\section{Conclusions}

By way of conclusion, this study showed that PrtT, a putative transcription factor that regulates extracellular proteases, is not the major factor affecting the regulation of the two major extracellular proteases secreted by $P$. digitatum during the infection of citrus fruits and that this gene is not involved in P. digitatum virulence. Furthermore, the good results in decay control obtained in the present study with 1,10-phenanthroline, a well-known metal chelator, warrants the exploration of a new possible target in fungal control: Metal chelation as a means to restrict micronutrient availability to pathogens.

Author Contributions: A.-R.B., M.L.-P., and B.d.1.F. performed the experiments and analyzed the data; A.-R.B. and L.G.-C. wrote the manuscript; L.G.-C. conceived and designed the experiments.

Funding: Funding was partially provided by the Spanish Ministry of Economy and Innovation (AGL2014-55802-R, and AGL2017-88120-R, AEI/FEDER, UE) and the Generalitat Valenciana (PrometeoII/2014/027). A-RB acknowledges the support of the JAE-Doc program from the Spanish National Research Council (CSIC) co-founded by the European Social Fund. M.L.-P. was supported by a "Formación de Personal Investigador" scholarship (BES-2006-12983).

Acknowledgments: The technical assistance of Ana Izquierdo (IATA-CSIC, Valencia, Spain) is gratefully acknowledged.

Conflicts of Interest: The authors declare no conflict of interest.

\section{References}

1. Souza, P.M.d.; Bittencourt, M.l.d.A.; Caprara, C.C.; Freitas, M.d.; Almeida, R.P.C.d.; Silveira, D.; Fonseca, Y.M.; Ferreira Filho, E.X.; Pessoa Junior, A.; Magalhães, P.O. A biotechnology perspective of fungal proteases. Braz. J. Microbiol. 2015, 46, 337-346. [CrossRef] [PubMed]

2. Braaksma, M.; Smilde, A.K.; van der Werf, M.J.; Punt, P.J. The effect of environmental conditions on extracellular protease activity in controlled fermentations of Aspergillus niger. Microbiology 2009, 155, 3430-3439. [CrossRef] [PubMed]

3. Rao, M.B.; Tanksale, A.M.; Ghatge, M.S.; Deshpande, V.V. Molecular and biotechnological aspects of microbial proteases. Microbiol. Mol. Biol. Rev. 1998, 62, 597-635. [PubMed]

4. Engel, L.S.; Hill, J.M.; Caballero, A.R.; Green, L.C.; O'Callaghan, R.J. Protease IV, a unique extracellular protease and virulence factor from Pseudomonas aeruginosa. J. Biol. Chem. 1998, 273, 16792-16797. [CrossRef] [PubMed]

5. Gropp, K.; Schild, L.; Schindler, S.; Hube, B.; Zipfel, P.F.; Skerka, C. The yeast Candida albicans evades human complement attack by secretion of aspartic proteases. Mol. Immunol. 2009, 47, 465-475. [CrossRef] [PubMed]

6. Figaj, D.; Ambroziak, P.; Przepiora, T.; Skorko-Glonek, J. The role of proteases in the virulence of plant pathogenic bacteria. Int. J. Mol. Sci. 2019, 20, 672. [CrossRef] [PubMed]

7. Jashni, M.K.; Mehrabi, R.; Collemare, J.; Mesarich, C.H.; De Wit, P.J. The battle in the apoplast: Further insights into the roles of proteases and their inhibitors in plant-pathogen interactions. Front. Plant Sci. 2015, 6, 584. [CrossRef]

8. Billon-Grand, G.; Poussereau, N.; Fevre, M. The extracellular proteases secreted in vitro and in planta by the phytopathogenic fungus Sclerotinia sclerotiorum. J. Phytopathol. 2002, 150, 507-511. [CrossRef]

9. Redman, R.S.; Rodriguez, R.J. Characterization and isolation of an extracellular serine protease from the tomato pathogen Colletotrichum coccodes, and it's role in pathogenicity. Mycol. Res. 2002, 106, 1427-1434. [CrossRef]

10. Jashni, M.K.; Dols, I.H.M.; Iida, Y.; Boeren, S.; Beenen, H.G.; Mehrabi, R.; Collemare, J.; de Wit, P.J.G.M. Synergistic action of a metalloprotease and a serine protease from Fusarium oxysporum $\mathrm{f}$. sp. lycopersici cleaves chitin-binding tomato chitinases, reduces their antifungal activity, and enhances fungal virulence. Mol. Plant-Microbe Interact. 2015, 28, 996-1008.

11. Sanz-Martín, J.M.; Pacheco-Arjona, J.R.; Bello-Rico, V.; Vargas, W.A.; Monod, M.; Díaz-Mínguez, J.M.; Thon, M.R.; Sukno, S.A. A highly conserved metalloprotease effector enhances virulence in the maize anthracnose fungus Colletotrichum graminicola. Mol. Plant Pathol. 2016, 17, 1048-1062. [CrossRef] [PubMed] 
12. ten Have, A.; Espino, J.J.; Dekkers, E.; Van Sluyter, S.C.; Brito, N.; Kay, J.; González, C.; van Kan, J.A. The Botrytis cinerea aspartic proteinase family. Fungal Genet. Biol. 2010, 47, 53-65. [CrossRef] [PubMed]

13. Punt, P.J.; Schuren, F.H.J.; Lehmbeck, J.; Christensen, T.; Hjort, C.; van den Hondel, C.A.M.J.J. Characterization of the Aspergillus niger prtT, a unique regulator of extracellular protease encoding genes. Fungal Genet. Biol. 2008, 45, 1591-1599. [CrossRef] [PubMed]

14. Bergmann, A.; Hartmann, T.; Cairns, T.; Bignell, E.M.; Krappmann, S. A regulator of Aspergillus fumigatus extracellular proteolytic activity is dispensable for virulence. Infect. Immun. 2009, 77, 4041-4050. [CrossRef] [PubMed]

15. Hagag, S.; Kubitschek-Barreira, P.; Neves, G.W.P.; Amar, D.; Nierman, W.; Shalit, I.; Shamir, R.; Lopes-Bezerra, L.; Osherov, N. Transcriptional and proteomic analysis of the Aspergillus fumigatus $\Delta p r t T$ protease-deficient mutant. PLoS One 2012, 7, e33604. [CrossRef] [PubMed]

16. Sharon, H.; Hagag, S.; Osherov, N. Transcription factor PrtT controls expression of multiple secreted proteases in the human pathogenic mold Aspergillus fumigatus. Infect. Immun. 2009, 77, 4051-4060. [CrossRef] [PubMed]

17. Chen, L.; Zou, G.; Zhang, L.; de Vries, R.P.; Yan, X.; Zhang, J.; Liu, R.; Wang, C.; Qu, Y.; Zhou, Z. The distinctive regulatory roles of PrtT in the cell metabolism of Penicillium oxalicum. Fungal Genet. Biol. 2014, 63, $42-54$. [CrossRef]

18. Marcet-Houben, M.; Ballester, A.-R.; De la Fuente, B.; Harries, E.; Marcos, J.F.; González-Candelas, L.; Gabaldón, T. Genome sequence of the necrotrophic fungus Penicillium digitatum, the main postharvest pathogen of citrus. BMC Genomics 2012, 13, 646. [CrossRef]

19. Li, B.; Zong, Y.; Du, Z.; Chen, Y.; Zhang, Z.; Qin, G.; Zhao, W.; Tian, S. Genomic characterization reveals insights into patulin biosynthesis and pathogenicity in Penicillium species. Mol. Plant-Microbe Interact. 2015, 28, 635-647. [CrossRef]

20. Rawlings, N.D.; Barrett, A.J.; Thomas, P.D.; Huang, X.; Bateman, A.; Finn, R.D. The MEROPS database of proteolytic enzymes, their substrates and inhibitors in 2017 and a comparison with peptidases in the PANTHER database. Nucleic Acids Res. 2018, 46, D624-D632. [CrossRef]

21. López-Pérez, M.; Ballester, A.-R.; González-Candelas, L. Identification and functional analysis of Penicillium digitatum genes putatively involved in virulence towards citrus fruit. Mol. Plant Pathol. 2015, 16, 262-275. [CrossRef] [PubMed]

22. Frandsen, R.J.; Andersson, J.A.; Kristensen, M.B.; Giese, H. Efficient four fragment cloning for the construction of vectors for targeted gene replacement in filamentous fungi. BMC Mol. Biol. 2008, 9, 70. [CrossRef] [PubMed]

23. Crespo-Sempere, A.; Selma-Lázaro, C.; Martínez-Culebras, P.; González-Candelas, L. Characterization and disruption of the cipC gene in the ochratoxigenic fungus Aspergillus carbonarius. Food Res. Int. 2013, 54, 697-705. [CrossRef]

24. Solomon, P.S.; Ipcho, S.V.S.; Hane, J.K.; Tan, K.-C.; Oliver, R.P. A quantitative PCR approach to determine gene copy number. Fungal Genet. Rep. 2008, 55, 5-8. [CrossRef]

25. Ruijter, J.M.; Ramakers, C.; Hoogaars, W.M.H.; Karlen, Y.; Bakker, O.; van den Hoff, M.J.B.; Moorman, A.F.M. Amplification efficiency: Linking baseline and bias in the analysis of quantitative PCR data. Nucleic Acids Res. 2009, 37, e45. [CrossRef] [PubMed]

26. Pfaffl, M.W. A new mathematical model for relative quantification in real-time RT-PCR. Nucleic Acids Res. 2001, 29, e45. [CrossRef] [PubMed]

27. Ward, M. Chymosin production in Aspergillus. In Molecular Industrial Mycology: Systems and Applications in Filamentous Fungi; Leong, Ed.; Taylor \& Francis Group: Abingdon, UK, 1991; pp. 83-105.

28. Ballester, A.R.; Lafuente, M.T.; González-Candelas, L. Spatial study of antioxidant enzymes, peroxidase and phenylalanine ammonia-lyase in the citrus fruit-Penicillium digitatum interaction. Postharvest Biol. Technol. 2006, 39, 115-124. [CrossRef]

29. Bustin, S.A.; Benes, V.; Garson, J.A.; Hellemans, J.; Huggett, J.; Kubista, M.; Mueller, R.; Nolan, T.; Pfaffl, M.W.; Shipley, G.L.; et al. The MIQE guidelines: Minimum information for publication of quantitative real-time PCR experiments. Clin. Chem. 2009, 55, 611-622. [CrossRef]

30. Untergasser, A.; Nijveen, H.; Rao, X.; Bisseling, T.; Geurts, R.; Leunissen, J.A. Primer3Plus, an enhanced web interface to Primer3. Nucleic Acids Res. 2007, 35, W71-W74. [CrossRef] 
31. Shemesh, E.; Hanf, B.; Hagag, S.; Attias, S.; Shadkchan, Y.; Fichtman, B.; Harel, A.; Krüger, T.; Brakhage, A.A.; Kniemeyer, O.; et al. Phenotypic and proteomic analysis of the Aspergillus fumigatus $\Delta \operatorname{prt} T, \Delta x p r G$ and $\Delta x p r G / \Delta p r t T$ protease-deficient mutants. Front. Microbiol. 2017, 8, 2490. [CrossRef]

32. van Loon, L.C.; Rep, M.; Pieterse, C.M.J. Significance of inducible defense-related proteins in infected plants. Annu. Rev. Phytopathol. 2006, 44, 135-162. [CrossRef] [PubMed]

33. Lorito, M.; Broadway, R.; Hayes, C.; Woo, S.; Noviello, C.; Williams, D.; Harman, G. Proteinase inhibitors from plants as a novel class of fungicides. Mol. Plant-Microbe Interact. 1994, 7, 525-527. [CrossRef]

34. Joshi, B.N.; Sainani, M.N.; Bastawade, K.B.; Gupta, V.S.; Ranjekar, P.K. Cysteine protease inhibitor from pearl millet: A new class of antifungal protein. Biochem. Biophys. Res. Commun. 1998, 246, 382-387. [CrossRef] [PubMed]

35. Kim, J.-Y.; Park, S.-C.; Hwang, I.; Cheong, H.; Nah, J.-W.; Hahm, K.-S.; Park, Y. Protease inhibitors from plants with antimicrobial activity. Int. J. Mol. Sci. 2009, 10, 2860-2872. [CrossRef] [PubMed]

36. Martinez, M.; Abraham, Z.; Gambardella, M.; Echaide, M.; Carbonero, P.; Diaz, I. The strawberry gene Cyf1 encodes a phytocystatin with antifungal properties. J. Exp. Bot. 2005, 56, 1821-1829. [CrossRef]

37. Pernas, M.; López-Solanilla, E.; Sánchez-Monge, R.; Salcedo, G.; Rodríguez-Palenzuela, P. Antifungal activity of a plant cystatin. Mol. Plant-Microbe Interact. 1999, 12, 624-627. [CrossRef]

38. Raman, N.; Mahalakshmi, R.; Mitu, L. Bio-sensitive activities of coordination compounds containing 1, 10-phenanthroline as co-ligand: Synthesis, structural elucidation and DNA binding properties of metal (II) complexes. Spectrochim. Acta A Mol. Biomol. Spectrosc. 2014, 131, 355-364. [CrossRef]

39. Viganor, L.; Howe, O.; McCarron, P.; McCann, M.; Devereux, M. The antibacterial activity of metal complexes containing 1, 10-phenanthroline: Potential as alternative therapeutics in the era of antibiotic resistance. Curr. Top. Med. Chem. 2017, 17, 1280-1302. [CrossRef]

40. Hood, M.I.; Skaar, E.P. Nutritional immunity: Transition metals at the pathogen-host interface. Nat. Rev. Microbiol. 2012, 10, 525. [CrossRef]

41. Malavia, D.; Crawford, A.; Wilson, D. Chapter Three-Nutritional Immunity and Fungal Pathogenesis: The Struggle for Micronutrients at the Host-Pathogen Interface. In Adv. Microb. Physiol.; Robert, K.P., Ed.; Academic Press: Cambridge, MA, USA, 2017; Volume 70, pp. 85-103.

42. Potrykus, J.; Ballou, E.R.; Childers, D.S.; Brown, A.J.P. Conflicting Interests in the Pathogen-Host Tug of War: Fungal Micronutrient Scavenging Versus Mammalian Nutritional Immunity. PLoS Pathog. 2014, 10, e1003910. [CrossRef]

43. Spadaro, D.; Droby, S. Development of biocontrol products for postharvest diseases of fruit: The importance of elucidating the mechanisms of action of yeast antagonists. Trends Food Sci. Technol. 2016, 47, $39-49$. [CrossRef]

44. Albelda-Berenguer, M.; Monachon, M.; Joseph, E. Siderophores: From natural roles to potential applications. In Adv. Appl. Microbiol.; Gadd, G.M., Sariaslani, S., Eds.; Academic Press: Cambridge, MA, USA, 2019; Volume 106, pp. 193-225.

45. Barad, S.; Horowitz, S.B.; Moskovitch, O.; Lichter, A.; Sherman, A.; Prusky, D. A Penicillium expansum glucose oxidase-encoding gene, GOX2, is essential for gluconic acid production and acidification during colonization of deciduous fruit. Mol. Plant-Microbe Interact. 2012, 25, 779-788. [CrossRef] [PubMed]

46. Quilis, J.; Meynard, D.; Vila, L.; Avilés, F.X.; Guiderdoni, E.; San Segundo, B. A potato carboxypeptidase inhibitor gene provides pathogen resistance in transgenic rice. Plant Biotechnol. J. 2007, 5, 537-553. [CrossRef] [PubMed]

(C) 2019 by the authors. Licensee MDPI, Basel, Switzerland. This article is an open access article distributed under the terms and conditions of the Creative Commons Attribution (CC BY) license (http://creativecommons.org/licenses/by/4.0/). 